\title{
A first-year, first-semester observership placement to increase nursing students' satisfaction
}

\author{
Elizabeth Emmanuel ${ }^{* 1}$, Marilyn Chaseling ${ }^{2}$, Lewes Peddell ${ }^{2}$ \\ ${ }^{1}$ Faculty of Health, Southern Cross University, Australia \\ ${ }^{2}$ Faculty of Education, Southern Cross University, Australia
}

Received: June 13, 2021

DOI: $10.5430 /$ jnep.v11n11p64
Accepted: July 9, 2021

URL: https://doi.org/10.5430/jnep.v11n11p64

\begin{abstract}
This paper reports on a two-day nursing observership in the first semester of an undergraduate baccalaureate-nursing program in an Australian university. Of the 392 novice student nurses who completed the observership, 340 provided a written reflection on their experience. The qualitative data were analysed using constant comparative analysis from which four themes were identified. Student nurses reported that the observership provided them with an insight into the nursing world (66.4\%), was a revelation (46.4\%), met their expectations (16.4\%), and was transformative (7.3\%). These themes indicated that an observership at the start of a nursing student's study can provide a professional socialisation experience, link new knowledge to practice, and ease that transition into nursing study. The implication for practice for nurse educators is to consider innovative approaches such as an observership to overcome challenges that first-year nursing students reportedly experience.
\end{abstract}

Key Words: Observership, First-year students, Patient, Care

\section{INTRODUCTION}

\subsection{Need for innovation}

In Australia, the theoretical learnings and clinical skills for nursing practice are located in universities. The Nurse and Midwifery Board of Australia oversee these programs to ensure the standards and competencies of practice, essential for nursing registration, are being delivered. ${ }^{[1]}$ The Australian approach for clinical placement varies depending on the availability of placements and other influencing factors. A recent report by Schwartz ${ }^{[1]}$ maintains that the inconsistent approach by universities to first placement in terms of allocated time and quality supervision is not sustainable. Such an experience also needs to be satisfying for students. Generally, this is not the case particularly with first clinical placements. ${ }^{[2-6]}$
Early clinical experience provides essential connections to classroom learning. Yet, literature shows that nursing students struggle to connect between what they learn at university and their first placement. ${ }^{[5,6]}$ Their struggle could be due to their clinical experience not aligning well with the classroom learning and, therefore, leading to dissatisfaction. ${ }^{[7]}$ Alternatively, there may be underlying conditions that interfere with students making connections, such as their apprehensions, ${ }^{[8]}$ unpreparedness ${ }^{[5]}$ or feelings of being unsupported.$^{[7]}$ Facilitating such connections for novice nursing students is essential as clinical experiences provide opportunities for students to learn about the why, what, where, when and how of nursing knowledge (classroom learning) and practice (clinical skills). ${ }^{[7]}$ For many students, the connections between the two settings do not occur spontaneously, and thus the learning experience is hindered. Hence, inno-

*Correspondence: Elizabeth Emmanuel; Email: elizabeth.emmanuel@scu.edu.au; Address: Faculty of Health, Southern Cross University, Australia. 
vative strategies are needed to assist students to make the connections between their classroom learning and clinical placement.

\subsection{A 'juggling act' spilling over into the placement ex- perience}

A steep increase in students enrolling into nursing programs in Australia has led to an insufficient number of clinical placements. Not surprisingly, competition for placements between education providers has been intense. ${ }^{[1]}$ As a result, placing students in quality, clinically-relevant areas has become more like a continuous juggling act for many education providers. ${ }^{[9]}$ At the same time, clinical facilities are also grappling with supporting the demand for placement due to internal socio-economic and political restraints. ${ }^{[1]}$ For nursing students, their first placement is usually towards the end of their second semester of university. By this time, they have accumulated a two-semester knowledge base to prepare them to enter the clinical learning environment. However, the late placement in the first year can create a misalignment of new nursing knowledge and related practice concepts and skills, which is not necessarily conducive to learning. This can lead to student apprehension and dissatisfaction.

\subsection{Retention}

Student satisfaction relies on a positive first-year experience, which, for education providers, improves retention rates. Therefore, a student-centric focus in first year is critical and can enhance the transition into nursing studies. ${ }^{[10]}$ Chan et al. ${ }^{[11]}$ identified several themes that contribute to retention, including pre-enrolment factors, delivery of curriculum and its content, set-up of clinical placement, and available support services for students. Within these, several risk factors are often at play, such as students with low efficacy, poor motivation, poor stress management skills, and unrealistic expectations. Clinical placement issues are also a common source of disillusionment for students. ${ }^{[12]}$ These reviews, though, did not indicate when in the first year the studies took place. A subsequent study by Nejad et al. ${ }^{[13]}$ investigated students' satisfaction levels with their first clinical placement, which occurred in their second or third semester. This quantitative study showed that students scored high satisfaction rates with their instructors' behaviour but low satisfaction rates on the atmosphere and learning in the clinical setting. Students described the atmosphere where they did not encounter 'friendliness' (20.4\%) and where the environment did not create a good sense of what it must be like to be a nurse $(10.8 \%)$.

\subsection{Value of observerships}

From the discussion to date, students need their first placement to provide a positive experience in which they can Published by Sciedu Press have early socialisation into nursing and develop their practice skills. One strategy that has worked well in medicine is observership placements, which allow learners to have pre-clinical, observational experience. While observerships have been used effectively in medicine, ${ }^{[13-15]}$ they are not frequently reported in nursing. One such report described community nurses completing a four-week clinical observership to expand their practice role. This allowed for more supportive and cost-effective care for patients in their homes. ${ }^{[16]}$ Another study reported on a nine-week observership program on Cognitive Behaviour Therapy as an interventive measure for women with postpartum depression. ${ }^{[17]}$ The program equipped the public health nurses involved to support mothers cope with postnatal depression and the demands of new motherhood. Hence, adapting observership as a first-year pre-clinical placement may be of great benefit, given the existing constraints of quality placements and the cost of clinical education.

\section{METHOD}

This paper explores the experiences and perceptions of novice nursing students after they had participated in a twoday observership placement in their first semester of study in a multi-campus regional university in Australia. The observership formed part of a foundational first-semester subject, in which students were introduced to the theory and practice of the essentials of nursing and care.

These essentials comprised of both philosophical understanding and practice relating to the construction of cognition, knowledge, reasoning, and concepts of caring. With this understanding, students can demonstrate introductory communication, observation, caring concepts, and assessment skills which underpins nursing practice and nurse-patient relationships.

The subject comprised six weeks of tutorials, four weeks of laboratory workshops, two weeks for oral presentations, followed by a two-day observership (see Figure 1). Assessments involved a quiz, written report, group presentation, and the two-day observational placement. To pass the placement, students needed to: (a) meet pre-placement requirements as specified by university and state health authorities; (b) complete the Professional Code of Conduct form; (c) attend 16 hours of placement, including undertaking a handwashing demonstration, and; (d) complete a pre- and post-placement workbook. The observership aimed for student nurses to draw on their learnings and readings from their university subject to appreciate the new professional and practice context of nursing. 


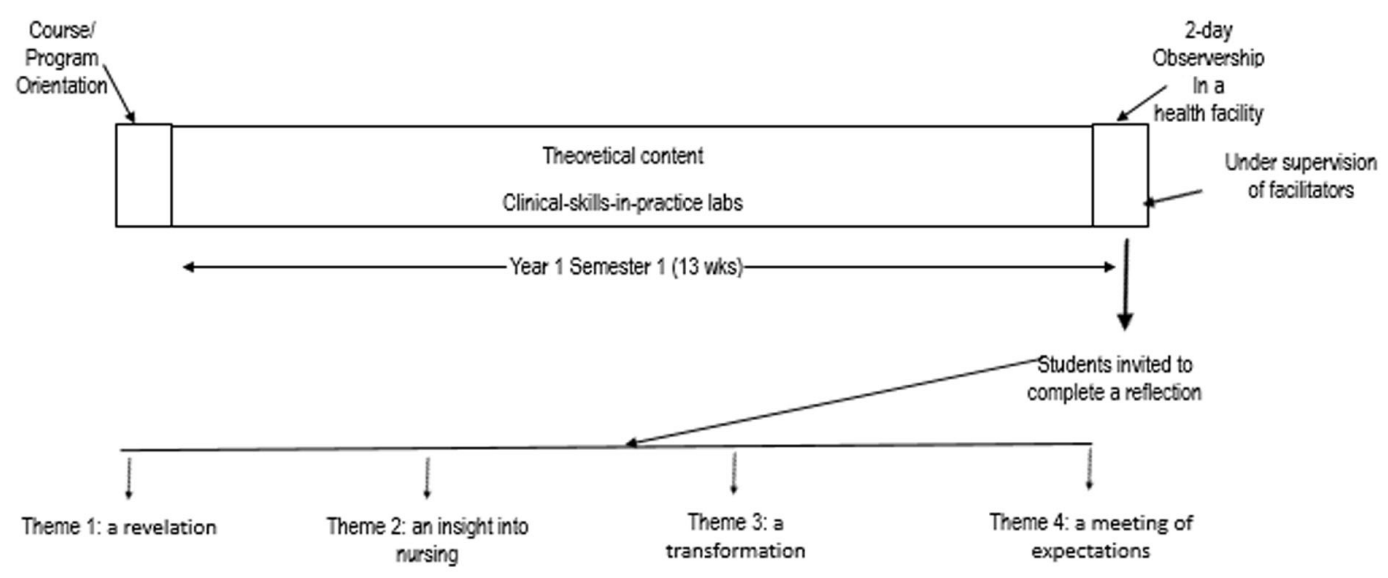

Figure 1. Overview of a first year, first semester subject

Embedded in the learning in this subject was reflective practice, which is linked to the development of selfconsciousness, and a way to critically reason. This practice is known to assist nursing students to develop their professional identity and behaviours, and finding meaning in what they do. This can help shape their future directions. ${ }^{[18]}$ To assist students with self-reflection, the SPROUT framework was introduced. ${ }^{[19]}$ This comprised a technique for remembering key concepts in which learners reflect on their thoughts, beliefs, and values; and how these might influence their actions in practice. In this way, students could begin to reflect on and make meaning of their course work, practice and observations.

For their observership, 392 students from a multi-campus regional university in Australia were placed at one of ten different health facilities distributed across two states. During the observership, qualified nurses supervised the students and facilitated a range of clinical nursing observations. Importantly, students were only permitted to observe, and not engage in any practice. After the observership, students were given the opportunity to write a reflection (narrative) on their clinical experience.

\section{RESULTS}

This study, approved by the University's Human Ethics Committee, used the qualitative approach of narrative inquiry to capture the students' reflective stories and explore their diverse observership experiences. ${ }^{[20]}$ Of the 392 students enrolled in the subject, 340 (87\%) completed a reflection. For de-identification, each participant's reflections were assigned a code that related to the health facility (e.g. C12, G30). Reflections were then analysed using constant comparative method, an iterative process whereby categories of meaning were generated, and similar thematic units of meaning were grouped together. ${ }^{[20]}$ In addition, main themes were counted and expressed as percentages (see Table 1). The trustworthiness of the study was enhanced through Lincoln and Guba's ${ }^{[21]}$ four techniques: i) credibility through triangulating the study's themes with feedback from the observership facilitators; ii) transferability through thick description; iii) dependability through reporting the study in detail (see Figures 1 and 2); and iv) confirmability through two of the researchers reviewing the data independently, then crosschecking the results.

\subsection{Students' demographics and satisfaction with the subject}

The student sample in this study was representative of firstyear nursing enrolments at this regional university that consist of a majority of domestic (98\%), mainly female (86\%) nursing students. Students' age ranged from 18 to 55 years with $38 \%$ of the sample being less than 20 years of age. Approximately $95 \%$ of students spoke English as their first language and $37 \%$ identified as the first-in-their-family to study at university. In terms of geolocation, approximately $40 \%$ of the students came from inner regional Australia and $8 \%$ from outer regional Australia. About socio-economic status (SES), nearly $70 \%$ measured at mid SES, while just below $25 \%$ measured at low SES.

All 340 students who participated in the observership completed it successfully. When the students were asked to complete the University's student satisfaction survey on the subject, overall, they rated the subject as 4.13/5 where "5" was the highest possible rating. This was higher than the University average of 4.07/5 for the semester, and also higher than the subject rating for the previous year when an observership was not included. It is very possible, that this observership placement contributed to students' satisfaction as demonstrated in their reflections, and from informal feedback from clinical facilitators of the different health facilities. 

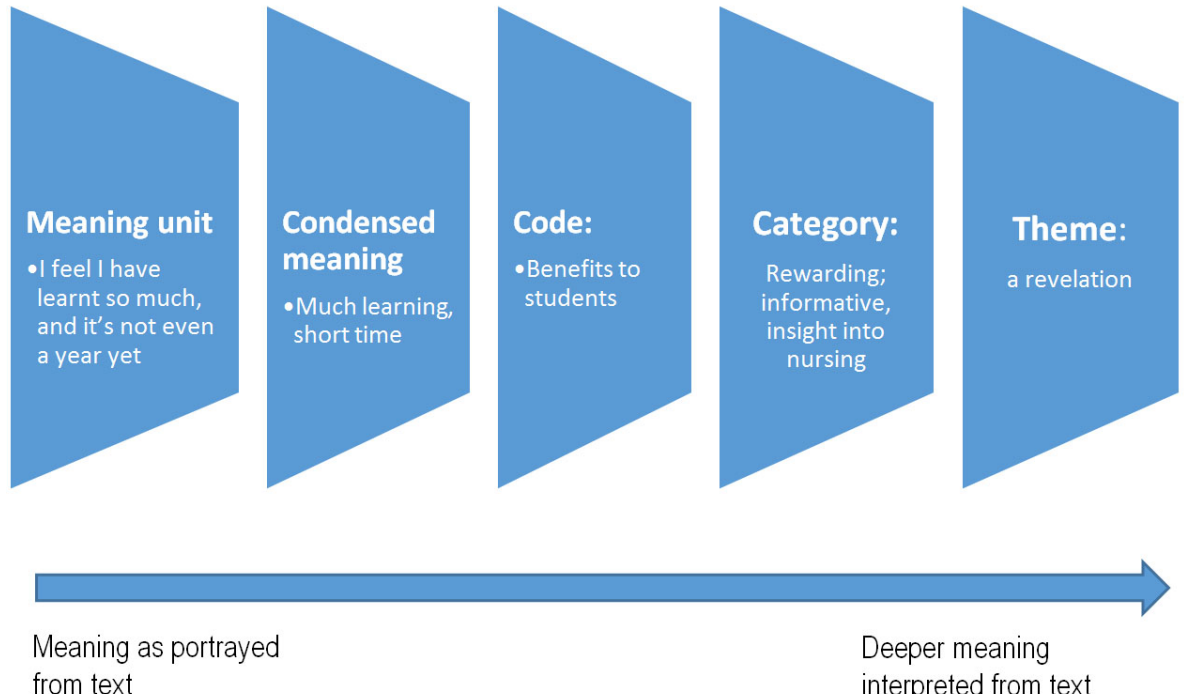

Deeper meaning

from text

Figure 2. Flow chart of content analysis

\subsection{Findings from the reflective narrative analysis}

The findings from the reflective narratives are reported here in order of the most recorded themes. Each theme is followed by representative student responses. Following the content analysis (see Figure 2), four main themes emerged (see Table 1). Collectively, these themes established what was important for these students in the observership. The most commonly reported theme $(66.4 \%)$ to emerge in the students' responses was that the observership provided an insight into the world of nursing. Two comments from these students represented this theme:

It was amazing to be able to step back and watch everything flow, interact with patients and understand how effective communication and teamwork are the foundation for great nursing care. I was able to gain a better understanding of what is required as a nurse, not having a patient load made it easier to really define nursing, as we were able to watch and learn. (E69)

This cemented how important nursing is and I have gained valuable experience that I will carry through my degree and career. (C15)

The second most reported theme $(46.4 \%)$ was that the observership was a revelation. The following responses are characteristic of this second theme:

Placement was informative and an excellent learning opportunity. Nurses were very accommodating and knowledgeable. They were patient with us when asked a question and slowed down their jobs so we could learn. (F8)

The 2 days of observations was a very useful learning experi- ence and gave me a taste of what registered nurses do every day. (B1)

The theme next most reported (16.4\%) was that students arrived at a meeting of [their] expectations. A representative sample of these comments was that:

...it provided me with a realistic idea of what the job requires, even if it was from the position of an observer. I could see the intensity of the teamwork, the need for clear communication, the understanding and support offered to one another. I saw how important it is to be aware of details in the treatment of patients. (C3)

I have enjoyed every moment and have learnt so much just from observing. (C13)

I came away feeling energized, informed and supported. (C9)

The final most reported theme, a transformation (7.3\%), indicated that the observership was transformational for students as outlined in these comments:

... I worried that I may not have what it takes to pursue a career in nursing. Due to the nurses and other staff and patients, I had the pleasure and honour to work alongside, these feelings have left me for good, and I now walk a little taller knowing that I have made the right decision. (E34)

Overall, I feel that the 2 days has prepared me for a profession that will be demanding, but very rewarding. (E24)

I was thoroughly impressed with J's guidance throughout the placement, and I feel I have gained immeasurable knowledge that has strengthened my passion for nursing and will aid me in the future. (D25) 
Table 1. Categories and themes on students' perceptions of observational placement

\begin{tabular}{|c|c|c|c|c|}
\hline Category & Responses & Deeper meaning & Sub-theme & Theme \\
\hline $\begin{array}{l}\text { Warm and welcoming; } \\
\text { early socialisation } \\
\text { opportunities }\end{array}$ & $43.8 \%,(n=149)$ & $\begin{array}{l}\text { Placement provided a unique } \\
\text { view and early socialisation into } \\
\text { nursing. Nursing staff were } \\
\text { welcoming and the opportunity } \\
\text { was most enjoyable }\end{array}$ & $\begin{array}{l}\text { A window into the } \\
\text { nursing world }\end{array}$ & \multirow{5}{*}{$\begin{array}{l}\text { An insight into the } \\
\text { nursing world (66.4\%) }\end{array}$} \\
\hline $\begin{array}{l}\text { Specialised; warm and } \\
\text { friendly }\end{array}$ & $4.1 \%,(n=14)$ & $\begin{array}{l}\text { Staff engaged in support and } \\
\text { giving of their time }\end{array}$ & $\begin{array}{l}\text { Staff willing and } \\
\text { giving }\end{array}$ & \\
\hline $\begin{array}{l}\text { Need for hands on; more } \\
\text { time }\end{array}$ & $4.4 \%,(n=15)$ & $\begin{array}{l}\text { Concerns that learning needs of } \\
\text { students' needs greater emphasis } \\
\text { with more focus on hands on and } \\
\text { time }\end{array}$ & $\begin{array}{l}\text { Need for more } \\
\text { student focus }\end{array}$ & \\
\hline $\begin{array}{l}\text { Poor use of time; } \\
\text { observations } \\
\text { challenging; } \\
\text { unable to assist }\end{array}$ & $10 \%,(n=34)$ & $\begin{array}{l}\text { Better use of time, mere } \\
\text { observation, and an inability to } \\
\text { get involved is problematic }\end{array}$ & Challenges & \\
\hline $\begin{array}{l}\text { More involvement; } \\
\text { more say; } \\
\text { cannot wait for more }\end{array}$ & $4.1 \%,(n=14)$ & $\begin{array}{l}\text { Need to have a say in level of } \\
\text { involvement and participation, as } \\
\text { need to assist was very strong }\end{array}$ & Having a say & \\
\hline $\begin{array}{l}\text { Informative; } \\
\text { insight into nursing; } \\
\text { rewarding/enjoyable }\end{array}$ & $32.6 \%,(n=111)$ & $\begin{array}{l}\text { Many benefits obtained. } \\
\text { Theoretical and practical nursing } \\
\text { knowledge was a transformative } \\
\text { learning experience }\end{array}$ & An 'aha' experience & \multirow[t]{2}{*}{$\begin{array}{l}\text { A revelation } \\
(46.4 \%)\end{array}$} \\
\hline Next placement & $14 \%,(n=48)$ & $\begin{array}{l}\text { Looking forward and excited } \\
\text { about future clinical placement }\end{array}$ & Enticing future & \\
\hline $\begin{array}{l}\text { Satisfaction with } \\
\text { learning and } \\
\text { knowledge; } \\
\text { self-satisfaction; } \\
\text { satisfaction with what is } \\
\text { in store }\end{array}$ & $6.7 \%,(n=23)$ & Exceeded expectations & $\begin{array}{l}\text { Met expectations } \\
\text { and more }\end{array}$ & \multirow[t]{2}{*}{$\begin{array}{l}\text { A meeting of } \\
\text { expectations } \\
(16.4 \%)\end{array}$} \\
\hline Gratitude & $9.7 \%,(n=33)$ & $\begin{array}{l}\text { Grateful for the time and } \\
\text { guidance }\end{array}$ & Appreciation & \\
\hline $\begin{array}{l}\text { Staff stress level; } \\
\text { comfort level; } \\
\text { enlightened }\end{array}$ & $3.2 \%,(n=11)$ & Seeing things differently & A changed view & \multirow{2}{*}{$\begin{array}{l}\text { A transformation } \\
(7.3 \%)\end{array}$} \\
\hline Adequate & $4.1 \%,(n=14)$ & Adequate and purposeful & $\begin{array}{l}\text { Appropriate time for } \\
\text { observation }\end{array}$ & \\
\hline
\end{tabular}

A student-centred approach was fundamental in this subject with students encouraged to be partners with the university in the construction of their learning and success. As such, many students not only voiced their positive experiences but also where the observership needed improvement. Some comments included:

A third day would have been beneficial to continue this sense of belonging (on the ward), and confidence within the nursing team, and continue the learning and observation. (E15)

Another stated:
I would have liked a tour of the whole hospital and a look at the different wards and in turn, different styles and approaches in nursing. However, the placement was only two days and time was short. (D14)

The nurse facilitators overseeing students valued the observership as a precursor to actual clinical placement. They reported that class tutorials and clinical laboratory activities prepared students for their exposure to the clinical environment in a positive way. On completion of their observership students appeared to have a better understanding of their role regarding professionalism, socialisation, teamwork, commu- 
nication and patient safety.

As one facilitator reported:

$B$ presented himself in a professional manner, in full uniform, punctual \& prepared. He was keen \& interested to learn \& worked within his scope of practice. He participated in all group discussions \& activities. Great feedback was given about $B \&$ the way he communicated with the patients. (E10)

A common comment for students' learning was of this nature:

... developed confidence to contribute to discussions and seek learning opportunities. The reflections indicated the beginning understanding of analysing their own and other people's practice. (C49)

and

... ability to communicate appropriately with the patients and staff. She completed a practice/scenario nursing care plan after discussion and reviewing of actual plans. She was able to identify the correct needs and did seek confirmation to increase her understanding of the individualised needs. She observed handovers and understands the use of the tool ISBAR. She was able to perform hand hygiene consistently over the 2 days and observe the various forms of infection control practices. It was obvious that $X$ became comfortable in the ward environment as she maintained within her scope and guidelines. (E13)

\section{Discussion}

This two-day observership, across a range of acute and primary health care settings, provided nursing students, in their first semester of first-year, with the unique opportunity to experience a "window" into the world of nursing, and so watch nursing life up close. The benefits of this observership, as reported by students in their reflections, shows the potential for creative development of new first-year placement models As pointed out by Spence et al., ${ }^{[22]}$ there is an urgency to integrate innovative strategies to improve students' clinical learning. Although different to the conventional model, an observership provides first-year nursing students with the opportunity to contemplate and take into account various aspects of the clinical environment. As one student wrote, "It was amazing to be able to step back and watch everything flow". As such, the observership provides a preview of the dynamic and interactive forces that pervade health care settings and impact on the students' professional development. ${ }^{[7]}$ While the vast majority of student responses were positive, some students (15\%) suggested that the observership was a wasted opportunity because they felt helpless, frustrated and guilty that they were unable to assist the nursing staff on the wards. One student explained.
"I feel more could have been gained from being on the wards, if we could have helped the nurses more, such as; helping them make beds and other small tasks that do not involve direct patient contact. There was so much to see and learn, it was a shame more time was not allocated to shadowing the nurses." (C45)

Familiarising students with the nursing world before they participate in an actual clinical practice, allows for a safe environment wherein students can integrate theoretical learning from university with practical learning, without the actual hands-on experience. An observership placed at the beginning of a student's program also allows early "career checking". This involves observing the physical space, the psychosocial interactions, culture of the workplace, and the learning and teaching factors. ${ }^{[23,24]}$ The connection which the students reported they made between theoretical and practical nursing knowledge gained from their university studies and observership, aligns with what Mezirow ${ }^{[25]}$ described as a transformative learning experience, or as Chick and Meleis ${ }^{[26]}$ identified as a "passage", where the student moves from one state to another, that is from a nursing student to a professional nursing student.

Overall, listening to students' voices is paramount. Tinto ${ }^{[10]}$ reminds the reader that the university curriculum needs to pay heed to the students' perspectives in order to reduce attrition. Many first-year nursing students want to complete their nursing degree but need a placement model that promotes persistence. In particular, students need more attention given to their placement, support from facilitators and mentors, and need to be made to feel welcomed, and work with a good team of health professionals. ${ }^{[27]}$ Generally, attention to students' voices in the evaluation of teaching and learning is needed so that appropriate planning can be undertaken to improve student satisfaction and retention. ${ }^{[28]}$ Even when negative feedback is given, although few, attention is needed by tutors as it demonstrates taking personal situations into account such as skill level or professional knowledge. ${ }^{[8]}$

However, clinical placement and students' perceptions attract less attention, and therefore lead to missed opportunities. While this study's results offer a pre-clinical placement in the form of an observership as a first introduction to the nursing environment, it may assist in keeping students motivated to continue their studies.

Of the 392 students enrolled in the subject, 52 did not provide a reflective response on their observership. The reflective component, on which this study is based, was an optional section, with no particular questions or directions. It attracted no grading. Non-responders may have been dissatisfied with their placement and therefore lacked interest in providing a 
written reflection. It is possible that students being first years, were unfamiliar with reflective writing and its importance in nursing, despite its coverage within the subject.

It is plausible that for many students, the observational placement provided an experience where complex concepts taught in the unit of study seemed to come together and make sense. As reported by Cioffi, ${ }^{29]}$ insights from clinical exposure have not been well reported and therefore there is little understanding of the learning experience. In the case of this observership, the experience was well appreciated by firstyear nursing students. They found it beneficial and motivating. More research on such a strategy is warranted with forward planning and collaboration between health facilities and universities.

\section{Conclusion}

It is clear from this study, that a relatively short observership_-only two-days_-in a nursing student's first semester provides many opportunities and advantages. A short observership is not overly demanding of students in terms of unduly intruding on their university contact time, or their time to complete their assignments. Nor is a short observership overly taxing on the host health facilities, nor on the cost to the university in terms of paying supervising staff. While there is a cost to universities in terms of organising observerships, this study indicates that the benefits far outweigh the cost.
As a first placement, observerships give aspiring nursing students an opportunity to observe nursing up close within the clinical learning environment, a real-world look-in for students, a chance to see if they really want to be a nurse. For many first years, this resonates well, because it is the beginning of a career, a chance for them to see how nurses practice at a professional level.

During the course of observation, no evidence of practical skill development occurs but the learning provides an insight into nursing practice and procedures, and how nurses function within the workplace. The very nature of an observership for students means that it provides safety for patients and the health facilities, but most importantly promotes a strong connection to nurses and the nursing world of everyday practice.

Given the overall positiveness in the students' reflections about their time in the observership, it would seem reasonable that students will feel less anxiety, stress, and apprehension than what nursing students normally experience (e.g. see Levett-Jones et al., ${ }^{[2]}$ with their first 'real' clinical placement). This could be because an observership promotes a gradual paradigm shift with little disruption required in the new environment. ${ }^{[26]}$ Creating an observership through the joint efforts of health facilities, nurse clinicians and other health professionals can provide an appropriate introduction to meet first-year nursing students' needs.

\section{Conflicts of Interest Disclosure}

The authors declare that there is no conflict of interest.

\section{REFERENCES}

[1] Schwartz S. Educating the Nurse of the Future -Report of the Independent Review into Nursing Education 2019, Commonwealth of Australia.

[2] Levett-Jones $\mathrm{T}$, et al. What are the primary concerns of nursing students as they prepare for and contemplate their first clinical placement experience? Nurse Education in Practice. 2015; 15(4): 304-309. PMid:25862609 https ://doi.org/10.1016/j.nepr.2015.03 .012

[3] Cooper J, Courtney-Pratt H, Fitzgerald M. Key influences identified by first year undergraduate nursing students as impacting on the quality of clinical placement: A qualitative study. Nurse Education Today. 2015; 35(9): 1004-1008. PMid:25828091 https: //doi.org/10.1016/j.nedt.2015.03.009

[4] Thomas J, Jinks A, Jack B. Finessing incivility: The professional socialisation experiences of student nurses' first clinical placement, a grounded theory. Nurse Education Today. 2015; 35(12): e4-e9. PMid:26358630 https://doi.org/10.1016/j.nedt.2015.08 .022

[5] Najafi Kalyani M, et al. How do nursing students experience the clinical learning environment and respond to their experiences?
A qualitative study. BMJ Open. 2019; 9(7): 1-8. PMid:31350243 https://doi.org/10.1136/bmjopen-2018-028052

[6] Bhurtun $\mathrm{H}$, et al. Stress in the clinical learning environment: Perceptions of first-year Finnish nursing students. Nursing Education Perspectives. 2021; 42(1): 2-6. PMid:32604266 https : //doi .or g/10.1097/01. NEP.0000000000000693

[7] Papastavrou E, et al. Nursing students' satisfaction of the clinical learning environment: a research study. BMC Nursing. 2016; 15(1): 44. PMid:27436992 https://doi.org/10.1186/s12912 -016-0164-4

[8] Bhurtun H. Stress and coping strategies among Finnish nursing students in the clinical learning environment. Dissertation in Health Sciences, 581. 2020. University of Eastern Finland.

[9] Birk M, et al. The impact of clinical placement model on learning in nursing: A descriptive exploratory study. Australian Journal of Advanced Nursing. 2017; 34(4): 16-23.

[10] Tinto V. Through the eyes of students. Journal of College Student Retention: Research, Theory \& Practice. 2017; 19(3): 254-269. https : //doi .org/10.1177/1521025115621917

[11] Chan ZCY, et al. Curriculum design and attrition among undergraduate nursing students: A systematic review. Nurse Education Today. 
2019; 74: 41-53. PMid:30580180 https://doi.org/10.1016/j. nedt.2018.11.024

[12] Merkley B. Student nurse attrion: A half century of research. Journal of Nursing Education and Practice. 2016; 6(3): 71-75. https: //doi.org/10.5430/jnep.v6n3p71

[13] Nejad FM, et al. Investigation of nursing students satisfaction with the first clinical education experience in universities of medical sciences in Iran. Journal of Medicine and Life. 2019; 12(1): 75-82. PMid:31123529 https://doi.org/10.25122/jml-2018-0008

[14] Brickman AR, Wu V, Zevin B. Preparing for surgery observerships during medical school: A cross-sectional study. Journal of Surgical Education. 2020; 77(5): 1097-1105. PMid:32434687 https: //doi.org/10.1016/j.jsurg.2020.03.007

[15] Sayyahmelli S, et al. From ibni sina (avicenna) to present, history of international fellowship and observership: University of WisconsinMadison experience. Turk Neurosurg. 2020; 30(2): 159-162.

[16] Tay J, Khoo X. Community nursing in the United Kingdom: Applicability to Singapore. Singapore Nursing Journal. 2019; 46(1): 2-6.

[17] Van Lieshout R, et al. Public health nurse delivered group cognitive behavioral therapy (CBT) for postpartum depression: A pilot study. Public Heatlh Nursing. 2020; 37(1): 50-55. PMid:31523851 https://doi.org/10.1111/phn.12664

[18] Naber J, Markley L. A guide to nursing students' written reflections for students and educators. Nurse Education in Practice. 2017; 25: 1-4. PMid:28437690 https ://doi .org/10.1016/j . nepr . 2017. 04.004

[19] Irwin P, Coutts R. Learning through reflection. SPROUT: A schema to teach reflective practice. Journal of Education and Practice. 2017; 8(36): $1-8$.
[20] Ary D, et al. Introduction to Research in Education. US: Cengage Learning. 2009.

[21] Lincoln Y, Guba E. Naturalistic Inquiry 1985, Newbury Park, CA Sage Publications.

[22] Spence D, et al. Challenges to the provision of clinical education in nursing. Contemporary Nurse. 2019; 55(4-5): 458467. PMid:30987540 https://doi .org/10.1080/10376178.2 019.1606722

[23] Flott EA, Linden L. The clinical learning environment in nursing education: a concept analysis. J Adv Nurs. 2016; 72(3): 501-13. PMid:26648579 https://doi.org/10.1111/jan.12861

[24] Mbakaya BC, et al. Nursing and midwifery students' experiences and perception of their clinical learning environment in Malawi: a mixedmethod study. BMC Nursing. 2020; 19(1): 87. PMid:32943984 https://doi.org/10.1186/s12912-020-00480-4

[25] Mezirow J. An overview on transformative learning, in Contemporary Theories of Learning: Learning Theorists - In Their Own Words, K. Illeris, Editor. Routledge: New York; 2009.

[26] Chick N, Meleis A. Transitions: a nursing concern, in Transitions Theory, A. Meleis, Editor. Springer publishing Co. : New York, NY; 2010; 237-257.

[27] Ten Hoeve Y, et al. Dreams and disappointments regarding nursing: Student nurses' reasons for attrition and retention. A qualitative study design. Nurse Education Today. 2017; 54: 28-36. PMid:28458164 https://doi.org/10.1016/j.nedt.2017.04.013

[28] Allen J, Nichols C. Do you hear me? Student voice, academic success and retention. Student Success. 2017; 8(2): 123-129. https : //doi.org/10.5204/ssj.v8i2.387

[29] Cioffi JM. Insight and discovery in clinical nursing practice. Collegian. 2017; 24(2): 191-196. https://doi.org/10.1016/j.cole gn.2015.10.004 